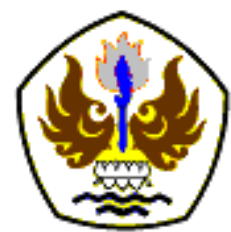

INFOMATEK

Volume 23 Nomor 2 Desember 2021

\title{
PERENCANAAN ULANG PROPELLER SHAFT PADA MOBIL TOYOTA KIJANG SUPER 1500CC TAHUN 1990
}

\author{
Dwiki Agung Saputra*, Jojo Sumarjo \\ Program Studi S1 Teknik Mesin \\ Fakultas Teknik - Universitas Singaperbangsa Karawang
}

\begin{abstract}
Abstrak: Mobil merupakan salah satu jenis kendaraan pribadi yang biasa digunakan dalam kehidupan seharihari. Kendaraan dapat berjalan/bergerak karena ada sistem yang memindahkan tenaga/momen/putaran dari mesin ke roda. Jenis dan merk tersebut juga banyak, salah satunya yaitu Kijang Super $1500 \mathrm{cc}$ dari Toyota. Mobil jenis ini memiliki komponen penting di antaranya body (bodi), machine (mesin), suspension (suspensi), electrical (kelistrikan), wheel (roda), chasis (rangka). Rangka merupakan salah suatu bagian penting dalam kendaraan. Komponen rangka sendiri terdiri dari flange yoke, propeller shaft, universal joint, sleeve yoke. Dari perhitungan diatas kita tahu bahwa: Tegangan aksial yang terjadi pada universal joint berdasarkan momen puntir yang transmisikan dari mesin sebesar 0,61 Mpa. Untuk menentukan kode bearing berdasarkan tabel 14/2 yang berbentuk konstruksi bantalan jarum sebesar 617 dan berdasarkan 14/1 yang sesuai dengan universal joint (bantalan jarum) dengan penyebutan lubang 01 mempunyai diameter dalam 12 dan diameter luar 21 jadi kode bearing yang didapat adalah NU 4901 E.MA.C2. Umur bearing yang dihitung berdasarkan tegangan aksial pada universal joint dengan putaran bearing sejumlah 372,4 jutaan putaran dapat bertahan sampai 1939,58 jam. Material bahan propeller shaft dan universal joint merupakan baja karbon rendah AISI 1045 dan AISI 4620 yang di rancang berdasarkan safety of factor sebesar 2 yang artinya material bahan aman.
\end{abstract}

Kata kunci: Mobil, Poros, Propeller Shaft

\section{PENDAHULUAN}

Mobil merupakan salah satu jenis kendaraan pribadi yang biasa digunakan dalam kehidupan sehari-hari. Kendaraan dapat berjalan/bergerak karena ada sistem yang memindahkan tenaga putaran. Tanpa adanya sistem pemindah tenaga maka kendaraan tak akan mungkin dapat berjalan (Juan, 2017 [1]). Jenis dan merk tersebut juga banyak, salah

\footnotetext{
*)1710631150075@student.unsika.ac.id

Pertama diterima: 13 Agustus 2021

Direvisi: 15 Oktober 2021

Disetujui untuk publikasi: 26 November 2021

DOI: 10.23969/infomatek.v23i2.4376
}

satunya yaitu Kijang Super 1500cc dari Toyota. Mobil jenis ini memiliki komponen penting di antaranya body (bodi), machine (mesin), suspension (suspensi), electrical (kelistrikan), wheel (roda), chasis (rangka). Rangka merupakan salah suatu bagian penting dalam kendaraan. Komponen rangka sendiri terdiri dari flange yoke, propeller shaft, universal joint, sleeve yoke.

Salah satu kompenen dari rangka yaitu propeller shaft. Propeller Shaft/poros kopel merupakan salah satu bagian dari pemindah 
tenaga dan poros ini terdapat pada tipe kendaraan FR (Front Wheel Rear Drive) dan 4WD (Four Wheel Drive) dimana jarak antara mesin dengan roda penggerak berjauhan sehingga memerlukan komponen tambahan agar dapat meneruskan tenaga putar dari mesin ke roda belakang. Propeller Shaft ini terletak antara transmisi dan differential (gardan) (Juan, 2017 [2]). Pada kendaraan kendaraan yang panjang, propeller dibagi menjadi beberapa bagian untuk menjamin supaya tetap dapat bekerja dengan baik. Suspensi kendaraan mengakibatkan posisi differensial selalu berubah-ubah terhadap transmisi, sehingga propeller harus dapat menyesuaikan perubahan sudut dan perubahan jarak, agar tetap mampu meneruskan putaran dengan lancar. Mekanisme atau komponen tersebut adalah universal joint. Propeller shaft juga merupakan penghubung antara poros transmisi dengan as roda belakang. Sedangkan universal joint yaitu salah satu bagian dari sistem pemindah tenaga yang berfungsi untuk memungkinkan poros berputar dengan lancar walaupun terjadi perubahan sudut (Anonim, 1989 [3]).

Pentingnya propeller shaft untuk meneruskan rotasi poros atau tenaga dari poros transmisi ke poros gardan. Oleh karena itu akan dirancangnya propeller shaft dengan menghitung dimensi dan material propeller shaft dari mobil Toyota Kijang Super 1500cc Tahun 1990. Maka dari itu perhitungan tersebut menjadi tolak ukur sebagai bahan pertimbangan penyusunan kajian ini.

\section{METODOLOGI}

\subsection{Diagram Alir Perhitungan dan}

\section{Perancangan Propeller Shaft}

Adapun diagram alir Perhitungan dan Perancangan Propeller Shaft sebagai berikut:

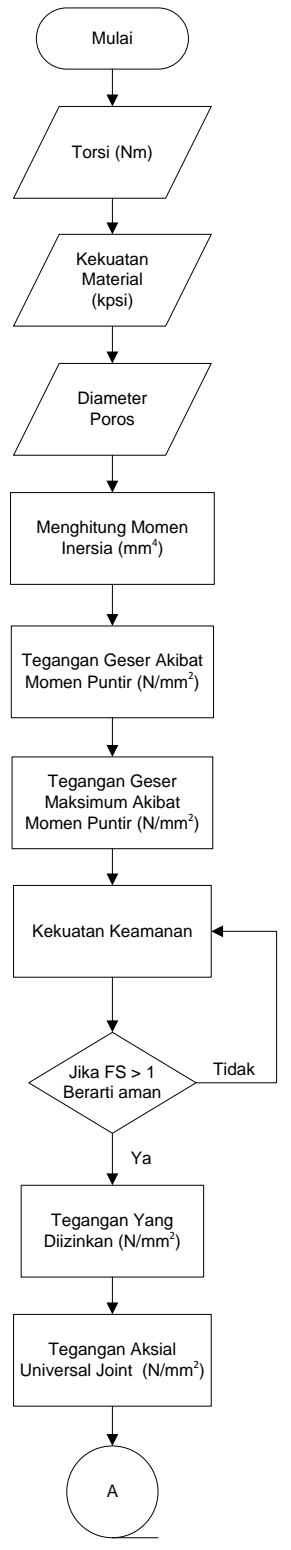




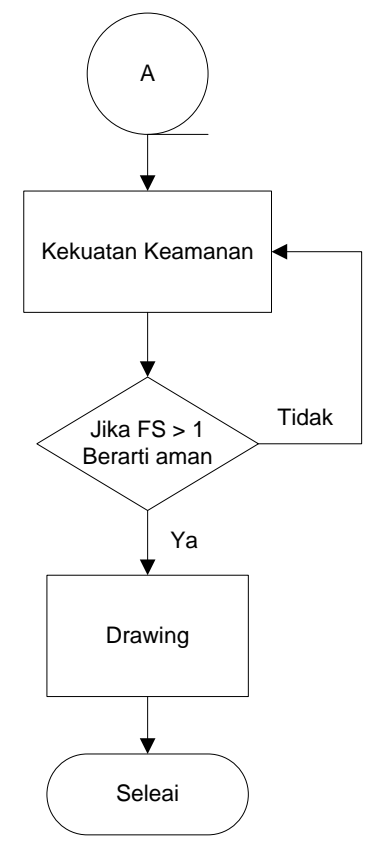

Gambar 1

Diagram Alir Perhitungan dan Perancangan Propeller Shaft.

\subsection{Spesifikasi Mobil Kijang Super $1500 \mathrm{CC}$} Tahun 1990

Adapun spesifikasi dari mobil super yaitu sebagai berikut (Anggraini, 2019 [4]):

Tabel 1

Spefifikasi Mobil Kijang Super 1500CC Tahun 1990

\begin{tabular}{ll}
\hline Tipe Mesin & $\begin{array}{l}\text { 4 Silinder OHV 8 Katup } \\
(5 \mathrm{~K})\end{array}$ \\
\hline $\begin{array}{l}\text { Diameter x } \\
\text { Langkah }\end{array}$ & $80,5 \mathrm{~mm}$ x $73 \mathrm{~mm}$ \\
\hline Kapasitas & $1500 \mathrm{cc}$ \\
\hline $\begin{array}{l}\text { Perbandingan } \\
\text { Kompresi }\end{array}$ & $9,0: 1$ \\
\hline Power Max & $63 \mathrm{Hp} / 4600 \mathrm{rpm}$ \\
\hline Torsi Max & $115 \mathrm{Nm} / 3200 \mathrm{rpm}$ \\
\hline Transmisi & Manual 4 Percepatan \\
\hline Tahun Produksi & 1986 - 1992 \\
\hline
\end{tabular}

\section{DIMENSI}

\begin{tabular}{ll}
\hline $\begin{array}{l}\text { Panjang x Lebar } \\
\text { x Tinggi }\end{array}$ & $1425 \mathrm{~mm} \times 1620 \mathrm{~mm} \times$ \\
\hline $\begin{array}{l}\text { Jarak Sumbu } \\
\text { Roda }\end{array}$ & $2500 \mathrm{~mm}$ \\
\hline $\begin{array}{l}\text { Kapasitas } \\
\text { Tangki Bahan } \\
\text { Bakar }\end{array}$ \\
\hline Berat Kosong & \\
\hline
\end{tabular}

\subsection{Spesifikasi Propeller Shaft Mobi Kijang} Super 1500CC Tahun 1990

Adapun spesifikasi dari mobil super yaitu sebagai berikut:

Tabel 2

Spefifikasi Propeller Shaft Mobil Kijang Super 1500CC Tahun 1990

\begin{tabular}{ll}
\hline Jenis Pengukuran & Hasil Pengukuran \\
\hline Panjang & $1327 \mathrm{~mm}$ \\
Diameter Luar & $83 \mathrm{~mm}$ \\
Diameter dalam & $78 \mathrm{~mm}$ \\
\hline
\end{tabular}

\subsection{Gambar 2D dan 3D Elemen Mesin}

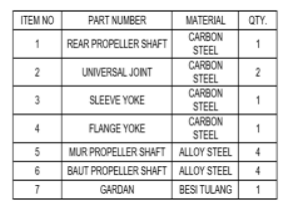

Gambar 2

Gambar 2D Propeller Shaft 


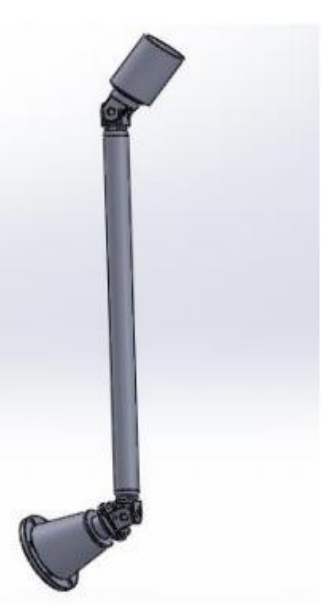

Gambar 3

Gambar 3D Propeller Shaft

\subsection{Photo Propeller Shaft}

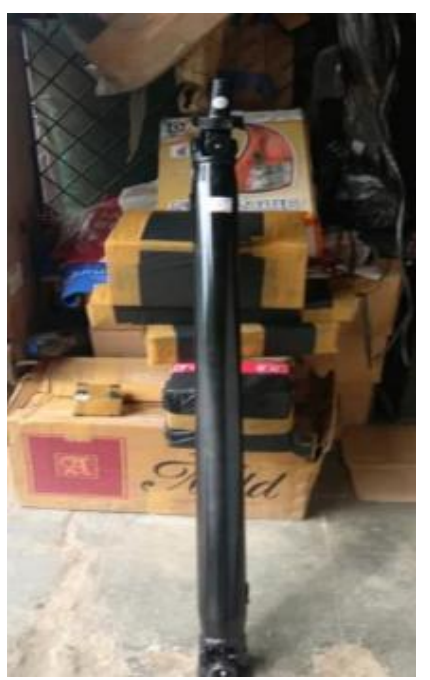

Gambar 4

Gambar Propeller Shaft

III. ANALISIS DAN PEMBAHASAN

\subsection{Analisa Momen Puntir Pada Poros}

a. DBB Momen Puntir Pada Poros

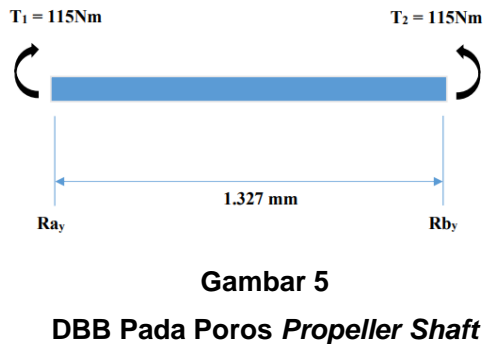

Rumus perhitungan Momen Puntir:

1. Menghitung Momen Puntir

$$
\begin{array}{ll}
\Sigma M x & =0 \\
\mathrm{~T} 2-\mathrm{T} 1 & =0 \\
\mathrm{~T} 1 & =\mathrm{T} 2 \\
115 \mathrm{Nm} & =\mathrm{T} 2
\end{array}
$$

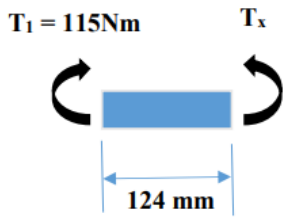

Gambar 6

DBB Momen Puntir Pada Poros Propeller Shaft

$\Sigma F y=0$

$\Sigma F x=0$

$F A=0 \mathrm{~T} 1-\mathrm{Tx}=0$

$115 \mathrm{Nm}-\mathrm{Tx}=0$

$\mathrm{Tx}$

$=115 \mathrm{Nm}$

b. Diagram Plom M

$115 \mathrm{Nm}$

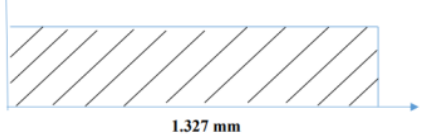

Gambar 7

Diagram Plot M 


\subsection{Perhitungan Perancangan Poros} Prolpeller Shaft

a. Menghitung Momen Inersia

Rumus menghitung momen Inersia (Sonawan, 2014 [8]).

$$
\begin{aligned}
J & =\frac{\pi\left(d^{4}\right)}{32} \\
& =\frac{3,14\left(83^{4}-78^{4}\right)}{32} \\
& =1.024 .745,38 \mathrm{~mm}^{4}
\end{aligned}
$$

b. Menghitung Tegangan Geser Akibat Momen Puntir atau Torsi

Rumus Menghitung tegangan geser akibat Momen Puntir atau Torsi [8].

$$
\begin{aligned}
\tau & =\frac{T \cdot \mathrm{r}}{J} \\
& =\frac{115000 \mathrm{Nmm} \times 41.5 \mathrm{~mm}}{1.024 .745,38 \mathrm{~mm} 4} \\
& =4,65 \mathrm{~N} / \mathrm{mm}^{2}
\end{aligned}
$$

c. Menghitug Tegangan Geser Maksimum Akibat Momen Puntir atau Torsi

Rumus menghitung tegangan geser maksimum akibat momen puntir atau torsi [8].

$$
\begin{aligned}
\tau \text { maks } & =\frac{\text { sy }}{2} \\
& =\frac{270}{2} \\
& =135 \mathrm{~N} / \mathrm{mm}^{2}
\end{aligned}
$$

d. Menghitung Safety of Factor (Faktor Keimanan)

Rumus menghitung safety of factor [8].

$$
\mathrm{FS}=\frac{\mathrm{sy}}{\tau \mathrm{maks}}
$$

$$
\begin{aligned}
& =\frac{270}{135} \\
& =2
\end{aligned}
$$

e. Menghitungkan Tegangan Geser Yang Diizinkan

Rumus menghitung tegangan geser yang diizinkan [8].

$$
\begin{aligned}
\text { tallowable } & =\frac{\frac{270}{2}}{2} \\
& =\frac{\frac{270}{2}}{2} \\
& =67.5 \mathrm{Mpa}
\end{aligned}
$$

\subsection{Perhitungan Perancangan Universal} Joint

a. Mengitung Tegangan Aksial Rumus

Rumus menghitung tegangan Aksial

$\mathrm{T}$

$$
=F 1 \cdot r 1+F 1 \cdot r 2+
$$$$
\text { F1. r3 }
$$

$\mathrm{T}$

$$
=4 \cdot \mathrm{F} 1(\mathrm{r} 1+\mathrm{r} 2+
$$$$
r 3+r 4)
$$

$11500 \mathrm{Nm}=4 . \mathrm{F} 1(24+24+$ $24+24)$

$\mathrm{F} 1$

$$
=115000 / 384
$$$$
=299.5 \mathrm{~N}
$$

$$
\begin{aligned}
\tau & =\mathrm{F} 1 / \mathrm{A} 1 \\
& =0.61 \mathrm{~N} / \mathrm{mm}^{2}
\end{aligned}
$$

b. Menghitung Safety of Factor (Faktor Keamanan)

Rumus menghitung safety of factor [8].

$$
\tau \text { maks }=\frac{\text { sy }}{2}
$$




$$
\begin{aligned}
& =\frac{89}{2} \\
& =44,5 \mathrm{~N} / \mathrm{mm}^{2}
\end{aligned}
$$

c. Menentukan Kode Bearing Yang Akan Digunakan

Berdasarkan tabel 14/1 dan tabel 14/2 (Niemann, 1986 [6]). Diperoleh kode bearing NU 4901 E.MA. C2 yang berarti bantalan rol silinder dari deretan ukuran 49 dengan pembatasan cincin luar, lubang bantalan $1 \mathrm{~mm}$. Kontruksi dalam yang dibedakan (diperkuat) dengan sarang kuningan masif diarahkan pada cincin luar dan ventilasi bantalan C2 (lebih besar dari normal).

d. Menghitung Umur Nominal Pada Bearing

Rumus menghitung umur nominal bearing $[6]$.

$$
\begin{aligned}
\mathrm{L} & =\left(\frac{C}{P}\right)^{\frac{10}{3}} \\
& =\left(\frac{F C \cdot I e f f^{\frac{7}{9}} \cdot z^{\frac{3}{4}} \cdot D w^{\frac{29}{27}}}{X \cdot F r+Y \cdot F a}\right)^{\frac{10}{3}} \\
& =\left(\frac{1,5(24)^{\frac{7}{9}} \cdot(24)^{\frac{3}{4}} \cdot(0,13[21+12])^{\frac{29}{27}}}{1 \cdot 0.61+0}\right) \frac{10}{3} \\
& =372,4 \text { jutaan putaran }
\end{aligned}
$$

e. Menghitung Umur Bearing

Rumus menghitung umur bearing (Jufri, 2017 [7]).

$$
\begin{aligned}
L h & =\frac{10^{6} \cdot \mathrm{L}}{(60 \cdot n)} \\
& =\frac{10^{6} \cdot 372,4}{(60 \cdot 3200)} \\
& =1939,58 \mathrm{jam}
\end{aligned}
$$

\section{KESIMPULAN}

Dari perhitungan dalam kajian ini, diperoleh beberapa hal yaitu:

a. Tegangan aksial yang terjadi pada universal joint berdasarkan momen puntir yang transmisikan dari mesin sebesar 0,61 Mpa.

b. Untuk menentukan kode bearing berdasarkan tabel 14/2 yang berbantuk konstruksi bantalan jarum sebesar 617 dan berdasarkan 14/1 yang sesuai dengan universal joint (bantalan jarum) dengan penyebutan lubang 01 mempunyai diameter dalam 12 dan diameter luar 21 jadi kode bearing yang didapat adalah NU 4901 E.MA.C2.

C. Umur bearing yang dihitung berdasarkan tegangan aksial pada universal joint dengan putaran bearing sejumlah 372,4 jutaan putaran dapat bertahan sampai 1939,58 jam.

d. Material bahan propeller shaft dan universal joint merupakan baja karbon rendah AISI 1045 dan AISI 4620 yang di rancang berdasarkan safety of factor sebesar 2 yang artinya material bahan tersebut aman.

Hasil perhitungan dan analisa belum bisa maksimal sehingga lebih baik lagi jika dilakukan perhitungan dan analisa lebih lengkap lagi agar bisa mendapatkan hasil 
yang lebih baik. Menggunkan sumber-sumber materi yang lebih baik lagi.

\section{DAFTAR PUSTAKA}

[1] Juan. (2017). Bagian atau Komponen Sistem Pemindah Tenaga dan Fungsinya. [Online]

Available at:

https://www.teknik-

otomotif.com/2017/03/bagian-ataukomponen-sistem-pemindah.html?m=1 [Accessed 10 Agustus 2021]

[2] Juan. (2017). Fungsi dan Komponen Poros Propeller Shaft. [Online]

Available at :

https://www.teknikotomotif.com/2017/04/fungsi-dankomponen-poros-propeller.html?m=1 [Accessed 10 Agustus 2021]

[3] Anonim, dkk. (1989). Fundamentals Of Servicing, PT Toyota-Astra Motor.
[4] Anggraeni, D. (2019). Kijang Super Harga, Spesifikasi, Kelebihan \& Kekurangan. [Online]

Available at:

https://www.google.com/amp/s/www.oto motifo.com/kijang-super-harga-danspesifikasi/\%3famp [Accessed 10 Agustus 2021]

[5] Sonawan H., Perancangan Eemen Mesin Edisi Revisi, Bandung: Alfabeta, 2014.

[6] Niemann G, dkk. Elemen mesin edisi Kedua Jilid I: Design dan Kalkulasi dan sambungan, bantalan dan poros, Jakarta:Erlangga, 1986

[7] Jufri, S., Mustari. (2017). Analisa Kerusakan Dan Umur Pakai Bantalan Gelinding Serta Kerugian Daya Pada Generator Merek Lindatlisensimen Type IFC 18045 H CB 3 - 2. Jurnal Dinamis, Vol 1 pp. $42-45$. 